Document downloaded from:

http://hdl.handle.net/10251/57449

This paper must be cited as:

Peydro, MA.; Parres, F.; Navarro Vidal, R.; Sanchez-Caballero, S. (2014). Study of the Influence of adding styrene-ethylene/butadiene-styrene in acrylonitrile-butadiene-styrene and polyethylene blends. Polymer Engineering and Science. 54(6):1313-1324. doi:10.1002/pen.23680.

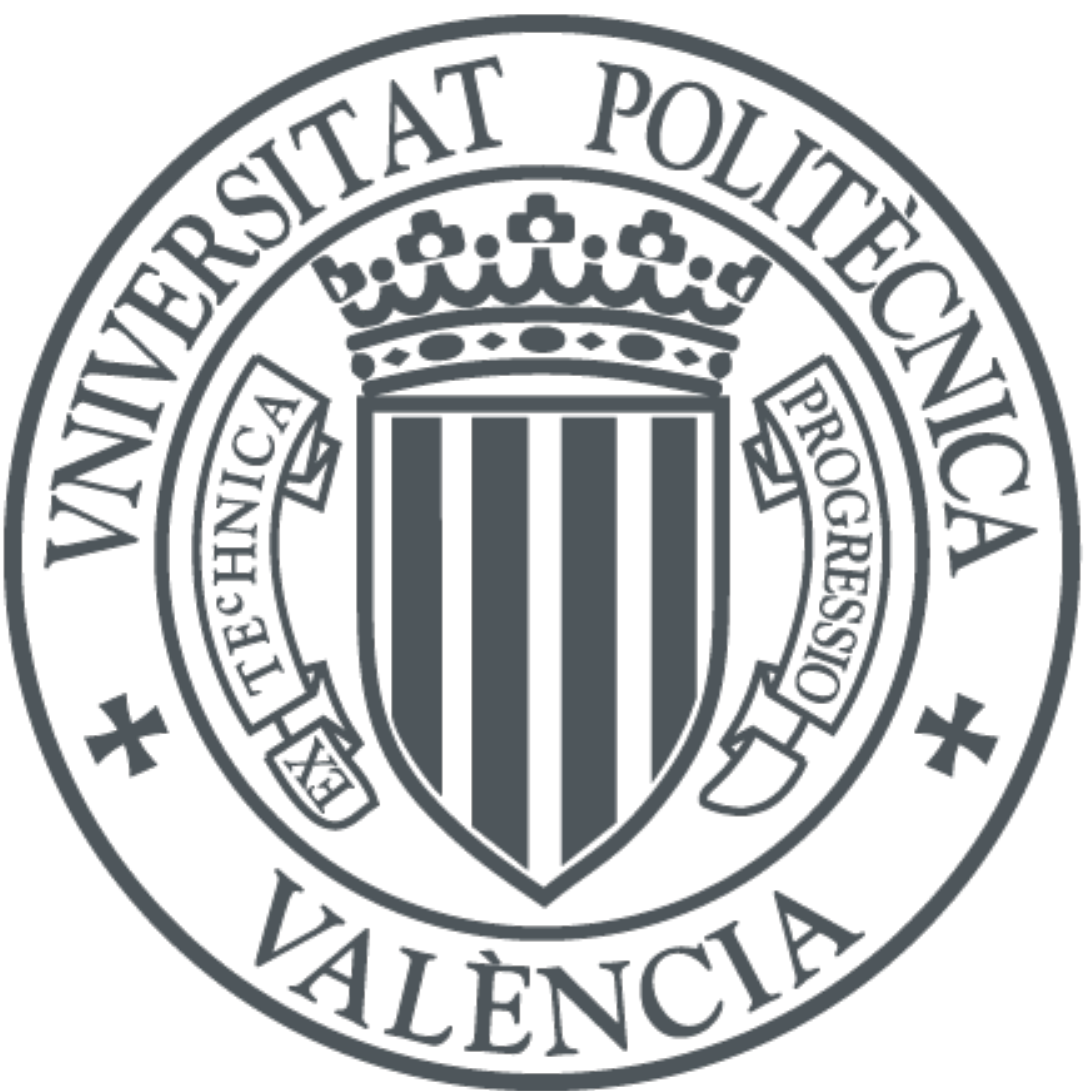

The final publication is available at

http://dx.doi.org/10.1002/pen.23680

Copyright Wiley-Blackwell

Additional Information 


\section{Study of the Influence of Adding Styrene- Ethylene/Butadiene-Styrene in Acrylonitrile-Butadiene-Styrene and Polyethylene Blends}

M.A. Peydro, F. Parres, R. Navarro, S. Sanchez-Caballero Departamento de Ingeniería Mecánica y de Materiales, Universitat Politécnica de Valencia (Campus de Alcoy), Plaza Ferrandiz y Carbonell, s/n 03801 Alcoy, Spain

\section{ABSTRACT}

This work studies the recovery of two grades of Acrylonitrile-Butadiene-Styrene (ABS) contaminated with Polyethylene (LDPE), by adding StyreneEthylene/Butadiene-Styrene (SEBS). To simulate contaminated ABS, virgin ABS was mixed with $1,2,4$ and $8 \%$ of LDPE and then extruded at $220{ }^{\circ} \mathrm{C}$. Following the highest contaminated ABS (8 \% LDPE) was mixed with 1, 2, 4 and $8 \%$ of SEBS and then extruded. Different blends were mechanically, rheologically, optically and dimensionally characterized to study how different percentages of LDPE and SEBS modify its properties.

The obtained results show how the tensile strength, Young modulus, elongation and impact strength linearly decrease as the LDPE amount increases, both for Natural and Black ABS. Through adding SEBS to contaminated ABS, it is possible to improve its strength and elongation values nearly to virgin ABS ones. However, its tensile strength and Young modulus are even slightly reduced.

Regarding to the rheological properties, the LDPE contamination in ABS causes a remarkable viscosity decrease, and adding SEBS to the blend even lowers its viscosity both for Natural and Black grades. This drop is not harmful but quite the reverse. The more fluid is the material, the easier is the mold injection. 
With regard to optical properties, two opposite effects take place: bleaching owed to LDPE addition and darkening and yellowing owed to the reprocessing process. However, the SEBS addition to the blend whitens the processed material.

\section{KEYWORDS}

Recovery, Blend, Contaminated, ABS, LDPE, SEBS.

\section{INTRODUCTION}

Recycled materials are characterized, not only by its processing temperatures, but also by its impurities content owed both to raw material and the recovery process. The studied material in this paper comes from security tag's recovery. The tag components are shredded altogether, so the outcome is a composite mix of ABS mainly contaminated with LDPE. This paper shows how adding SEBS can improve the mechanical properties of the ABS contaminated with LDPE.

In order to substitute a raw material by a recycled one, one of the most determinant factors is the keeping of the mechanical characteristics. Thermoplastic's properties are affected not only by thermal phenomena, but also by other physic phenomena as atmospheric ones, which constitutes an important shortcoming.

Present crisis has raised competitiveness in companies, pulling down production costs such as raw materials, waste production, process optimization, etc. Regarding to polymer processing companies, the economic crisis and the

oil price dependence have forced them to use recycled materials in order to achieve stable price levels. 
When the recovered plastics come from landfills, is neither technical nor economical viable, the usual option for these materials (usually LDPE, PP, PS, PVC, PET, ABS and aluminum blends) is incineration to produce energy. In such cases, ABS/LDPE blend studies, like Adrados [1] or Brebu [2], are interesting since they study the residue content after a pyrolysis treatment.

Maris [3] proposed an alternative to incineration where the plastics are ground, generating hard to sort complex blends. Furthermore, a high purity is unlikely to be achieved with actual physicochemical processes. To avoid this, automatic sorting systems, based on infrared spectroscopy, can be previously used to the grind process. Unfortunately, this can only be applied to dark materials. To overcome this drawback, Maris proposed to add markers in raw materials to allow a quick sorting using fluorescence ultraviolet spectrometry as identification technique. Maris proved that adding markers below $250 \mathrm{ppm}$ to polymer matrices has not influence on its mechanical properties.

Another alternative for non-compatible plastics, as ABS and LDPE, would be adding compatibilizers. For instance, Tasdemir used styrene-butadiene-styrene (SBS) [4] and styrene-isopren-styrene (SIS) [5] as ABS/PC blends compatibilizers. SBS and SIS are very similar to SEBS. However, there are no reports where SEBS were added to recovered polymers to make up its mechanical properties.

Other remarkable works are: Li [6], who studied PPO/PA with SEBS-g-MA blends and Yin [7], who studied PC/SAN with SEBS blends. These works are not comparable with the present one, but they gave the guidelines to improve the mechanical properties using SEBS.

Acrylonitrile-Butadiene-Styrene (ABS) is used in those cases when the surface appearance is important. ABS is a technical thermoplastic widely used in 
several sectors as automotive industry, electronic and electricity, etc. A good relationship between mechanical properties versus price, constitutes its main advantage, regardless some reprocessing problems, either injection or extrusion, due to the polybutadiene phase.

On the other hand, Oliveira correlated the injection molding parameters with the surface topology and brightness of $A B S$ sheets [8]. He proved that the surface finish and appearance of injection-molded parts are highly dependent on the mold texture and roughness, as well as the compaction pressure.

One of the fundamental properties to consider when studying polymer processing is its rheological behavior. Understanding this parameter is vital to carry out a correct extrusion or injection of the polymer. The real viscosity of a polymer is obtained using a capilliary rheometer along with the Bagley and Rabinowitsc corrections. The methodology used in this work to calculate the viscosity is the same as used by Peydro [9] in his study of HIPS, which is comprehensively explained in that work.

The reproduction of the mold surface onto the obtained part is driven by two conditions. First of all, a low viscosity when melted improves the contact between the polymer and the mold surface. Secondly, avoiding a cold surface when solidifying prevents from outer layer deformation during the mold filling. These two conditions are achieved on most of the mold surfaces when the melted mass temperature, the mold temperature, the flow speed and the retaining pressure are set on their maximum values. Regarding to ABS, Oliveira used a mass temperature of $260^{\circ} \mathrm{C}$, a mold temperature of $80^{\circ} \mathrm{C}$, a flow speed of $60 \mathrm{~cm}^{3} \cdot \mathrm{min}^{-1}$ and a compacting pressure of $900 \mathrm{kPa}$, to obtain the best surface finish. 
But, Oliveira also clearly proved that the most relevant parameter on surface brightness was the mold temperature. With a gleaming mold surface, a high mold temperature produces glossy parts. However, with a matt mold surface, a high mold temperature yields to fewer glossy parts.

These studies have been used to set up the processing parameters, as the flow temperature to $240{ }^{\circ} \mathrm{C}$, and mold temperature to $60{ }^{\circ} \mathrm{C}$. The flow speed was tuned to the highest value to avoid the maximum shear strength, and the compaction pressure to the largest to prevent from burr generation.

Other works like Salari [10], Tiganis [11], Arostregui [12] and Karahaliou [13, 14] studied the optical properties like the yellowing and darkening of ABS caused by thermo-oxidation, are interesting to compare our results.

The aim of present work is to achieve the recovery of two, ABS grades (natural and black) contaminated with LDPE through SEBS addition, while analyzing mechanical, rheological, optical and dimensional properties.

\section{EXPERIMENTAL}

\subsection{Material}

This work used the following commercial products: ABS Terluran GP $22 \circledast$ (BASF, Ludwigshafen, Alemania), LDPE ALCUDIA® PE063/A® (Repsol, Madrid España) and SEBS Megol TA 50® (Applicazioni Plastiche Industriali, Mussolente, Italia). Table 1 shows the most important properties for their selection.

Table 1. Materials used at present work. 


\begin{tabular}{lcccc}
\hline Material & Description & $\mathbf{K g} \cdot \mathbf{~ m}^{\mathbf{- 3}}$ & $\mathbf{c m}^{\mathbf{3}} \cdot \mathbf{1 0} \mathbf{~ m i n}^{\mathbf{- 1}}$ & Source \\
\hline ABS & Terluran GP 22 & 1040 & $19\left(220^{\circ} \mathrm{C}, 10 \mathrm{Kg}\right)$ & BASF \\
LDPE & ALCUDIA & 920 & $4\left(190^{\circ} \mathrm{C}, 2.16 \mathrm{Kg}\right)$ & Repsol \\
& PE063/A & & & \\
SEBS & Megol TA 50 & 890 & - & A P I \\
\hline
\end{tabular}

\subsection{Specimen preparation}

The ABS contaminated with LDPE was obtained using a twin-screw extruder, working at $220 \stackrel{\circ}{ }$. Four PEBD blends quantities of $1,3,4$ and $8 \%$ wt. were obtained for two ABS grades (natural and black). Prior to the extrusion process, the virgin $A B S$ was dried at $80{ }^{\circ} \mathrm{C}$ for four hours using a MDEU1/10 drier made by Industrial y Comercial Marse S.L.® (Barcelona, Spain).

On the other hand, ABS/LDPE with SEBS blends were obtained at the same working temperature, changing the SEBS ratio (1, 2, 4 and $8 \%$ wt.).

The flat specimens, used for optical, dimensional and mechanical characterization, were produced using a conventional injection machine Meteor 270/75 made by Mateu \& Solé® (Barcelona, Spain) working at $240 \stackrel{\circ}{ } \mathrm{C}$. Prior to the injection process, the virgin $A B S$ was dried at $80^{\circ} \mathrm{C}$ for four hours using a MDEU1/10 drier made by Industrial y Comercial Marse S.L.® (Barcelona, Spain).

\subsection{Mechanical characterization}

The specimens were tested using a universal tensile testing machine ELIB 30 made by S.A.E. Ibertest $\AA$ (Madrid, Spain) according to standard ISO 527. All the specimens had a length of $150 \mathrm{~mm}$ and a section of $10.4 \mathrm{~mm}^{2}$. They were tested at $25 \stackrel{\circ}{\circ}$, a relative humidity of $25 \%$ and a test speed of $50 \mathrm{~mm} \cdot \mathrm{min}^{-1}$, 
using a $5 \mathrm{KN}$ load cell. At least, ten specimens of each material were tested, computing the mean and standard deviation for elongation and strength at break.

The impact tests were done using a Charpy axial impact pendulum made by Metrotec ${ }^{\circledR}$ (San Sebastián, Spain) with adjustable masses for energy ranges from 1 to $6 \mathrm{~J}$, according to standard ISO 179 .

The hardness was measured using a Shore durometer made by Instruments J. Bot S.A. ${ }^{\circledR}$ (Barcelona, Spain), using a D scale in accordance with standard ISO 868.

\subsection{Rheological characterization}

The rheological analysis was done using a capillary rheometer ThermoHaake Rheoflixer MT® made by ThermoHaake (Dieselstr-Karlsruhe, Germany). The temperature was set at $240^{\circ} \mathrm{C}$ for ABS, LDPE and their blends. However, 180 $\stackrel{\circ}{ } \mathrm{C}$ and $200{ }^{\circ} \mathrm{C}$ values were used for SEBS due to its low viscosity. The shear speed was studied from $100 \mathrm{~s}^{-1}$ to $10000 \mathrm{~s}^{-1}$. The tests were conducted with three nozzles with a diameter of $1 \mathrm{~mm}$ and a length of 10,20 and $30 \mathrm{~mm}$. The tests fulfilled the standard ISO 11443. The viscosity values for each nozzle represent the mean of the measured values in five tests.

\subsection{Optical characterization}

The color measurement was carried out with a ColorFlex® colorimeter made by Hunter Associates Laboratory, Inc (Virginia, EEUU). This instrument was designed to determinate the color characteristics for the CIELAB system, according to the standards UNE 72031:1983 and UNE11664-4:2011. It uses three parameters for color definition: the luminance factor $(\mathrm{L})$, which measures the change from black (0) to white (100), the red saturation factor (a), which 
measures the color change from red (positive values) to green (negative), and the yellow saturation factor (b), which measures the color change from yellow (positive) to blue (negative).

\subsection{Dimensional characterization}

Flat specimens (Figure 1) used for optical and dimensional characterization, within a mold cavity with $160 \cdot 60 \cdot 2 \mathrm{~mm}^{3}$, were measured with a micrometer made by TESA ${ }^{\circledR}$ (Renens, Switzerland) with a measurement range from 150 to $175 \mathrm{~mm}$, and another made by Kalkum Ezquerra ${ }^{\circledR}$ (Los Fresnos-Haro, La Rioja, Spain), both with a precision of $0.001 \mathrm{~mm}$.

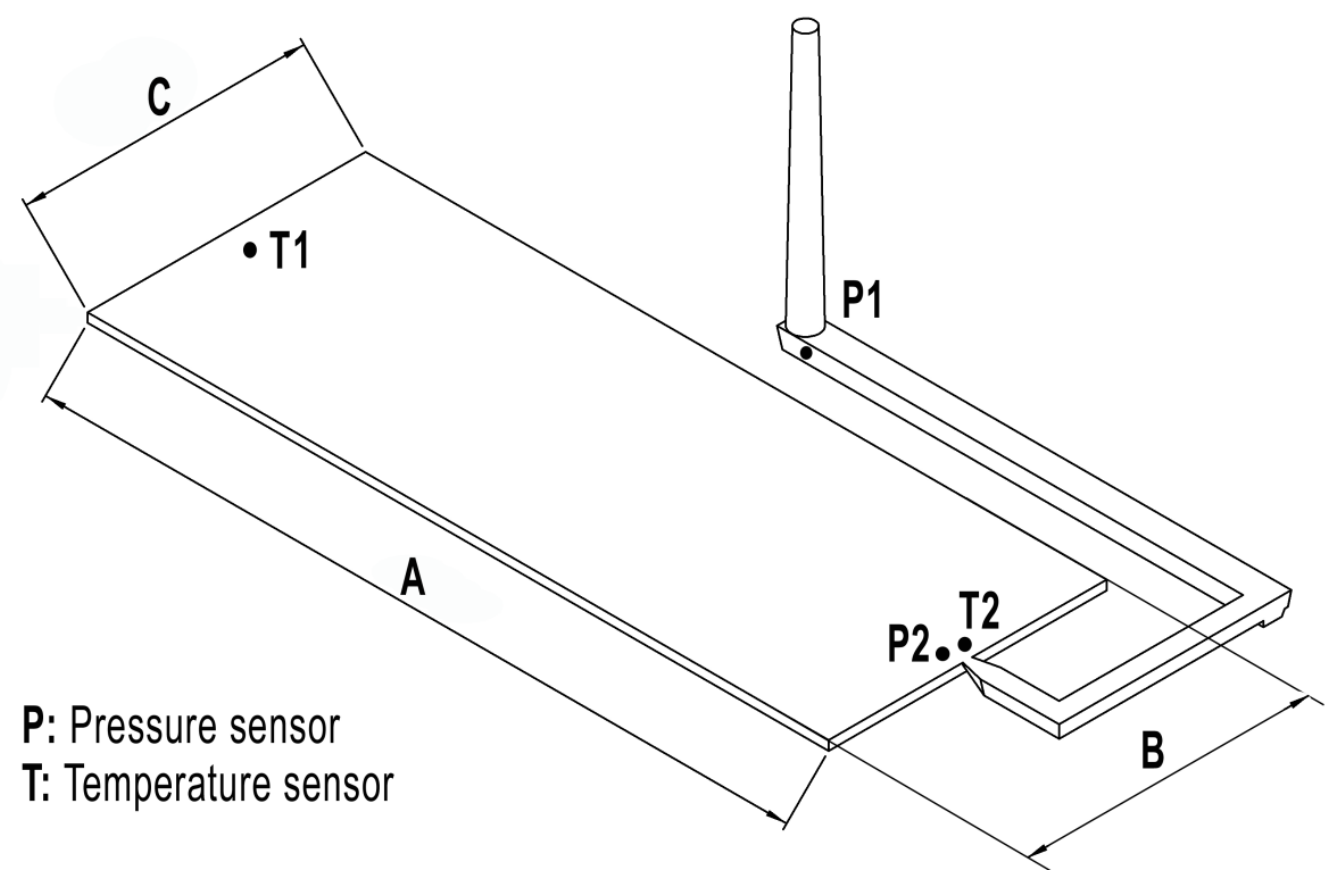

Figure 1. Molded part geometry.

\subsection{Other techniques}

The injection simulation tests were done using the CAE software Autodesk Moldflow Insight (version 2012) ${ }^{\circledR}$. The simulation results for the cavity were used to determinate the optimum injection conditions for the temperature 
preset, getting the speed, pressure and injection times to be used in the injection machine.

\section{RESULTS AND DISCUSSION}

\subsection{Characterization of ABS contaminated with LDPE.}

\subsubsection{Mechanical characterization.}

Both grades (natural and black) were studied to measure the color changes produced by adding LDPE and SEBS into virgin ABS. Indeed, both grades are the same, but with a different coloring additive. The source material is ABS Terluran GP $22 \AA$, meantime the natural and black grades only differ in the coloring additives.

Table 2 shows the material properties given for both grades. The results shown in Figure 2 assured the same mechanical behavior for both grades, with a slightly greater tensile strength for the black grade and lightly larger impact strength for the natural grade. Adding LDPE to ABS produces a linear decrease in the tensile strength, elongation and impact strength as the LDPE quantity is increased for both black and natural grades. Instead, any quantity of PEDB brings the elastic modulus to decrease from $90 \%$ to $95 \%$. Elongation is the most spoiled mechanical property, lowered up to $60 \%$, followed by the impact strength which is lowered to $35 \%$, and finally the tensile strength is reduced up to $20 \%$ for an $8 \%$ of LDPE at maximum.

The mechanical properties reduction is due to the ABS immiscibility with PEDB, [3]. 
Table 2. Mechanical properties data given by the manufacturers.

\begin{tabular}{lcccc}
\hline Material & $\begin{array}{c}\text { Young } \\
\text { modulus } \\
(\mathbf{M P a})\end{array}$ & $\begin{array}{c}\text { Tensile } \\
\text { strength } \\
\text { at 23 } \text { C } \\
(\mathbf{M P a})\end{array}$ & $\begin{array}{c}\text { Elongation at } \\
\text { break } \\
(\%)\end{array}$ & $\begin{array}{c}\text { Charpy } \\
\text { notched } \\
\text { impact } \\
\text { strength } \\
\left(\mathbf{k J} \cdot \mathbf{m}^{-2}\right)\end{array}$ \\
\hline ABS & 2300 & 45.0 & 10 & 22 \\
LDPE & - & 20.0 & 200 & $\mathrm{NB}$ \\
SEBS & 2.3 & 6.7 & 650 & $\mathrm{NB}$
\end{tabular}

NB: No breakage.
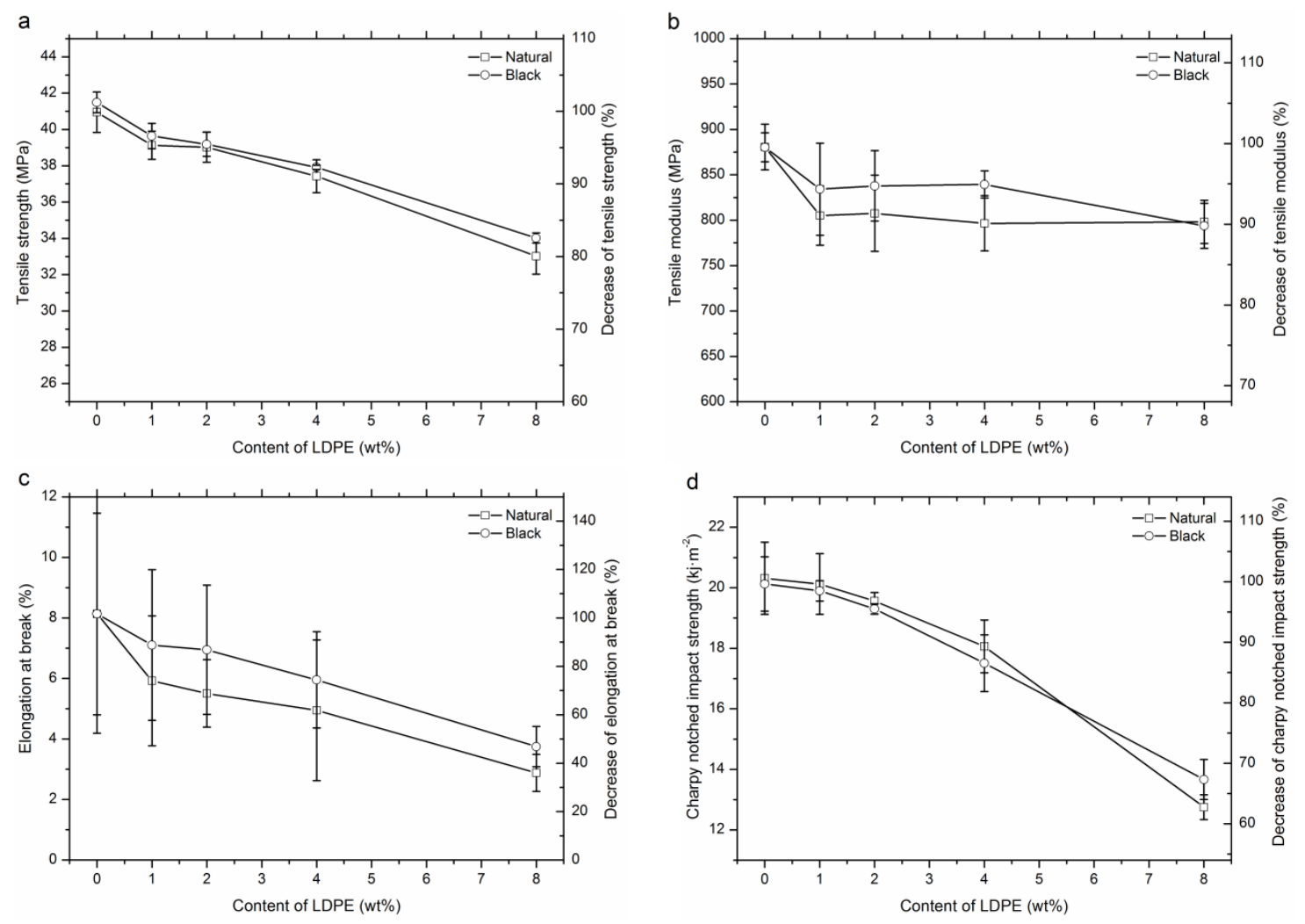
Figure 2. Mechanical properties of ABS/LDPE blends for Natural and Black

Grades.

\subsubsection{Rheological characterization.}

The rheological behavior is one of the most important properties for polymer processing, since it defines the adequate parameters for polymer injection or extrusion.

The rheological characterization of virgin and processed materials was carried out using a capillary rheometer as this equipment moves with a fixed speed. The measured pressure and speed were used to compute the shear stress $(T)$ and the shear rate $(\gamma)$, using the Bagley and Rabinowitsch corrections. The viscosity was computed according to eq. (1).

According to the standard, three nozzles were used, obtaining three viscosity curves for each material. Through an iteration process performed by MathCad $2001 \AA$, a unique curve was obtained for each material. Figure 3 shows the computed viscosity curves for virgin materials. A slight difference can be observed between both ABS grades. As can be seen, LDPE has a lower viscosity than the ABS but quite higher than SEBS.

$\eta=\frac{\tau}{\gamma}$ 


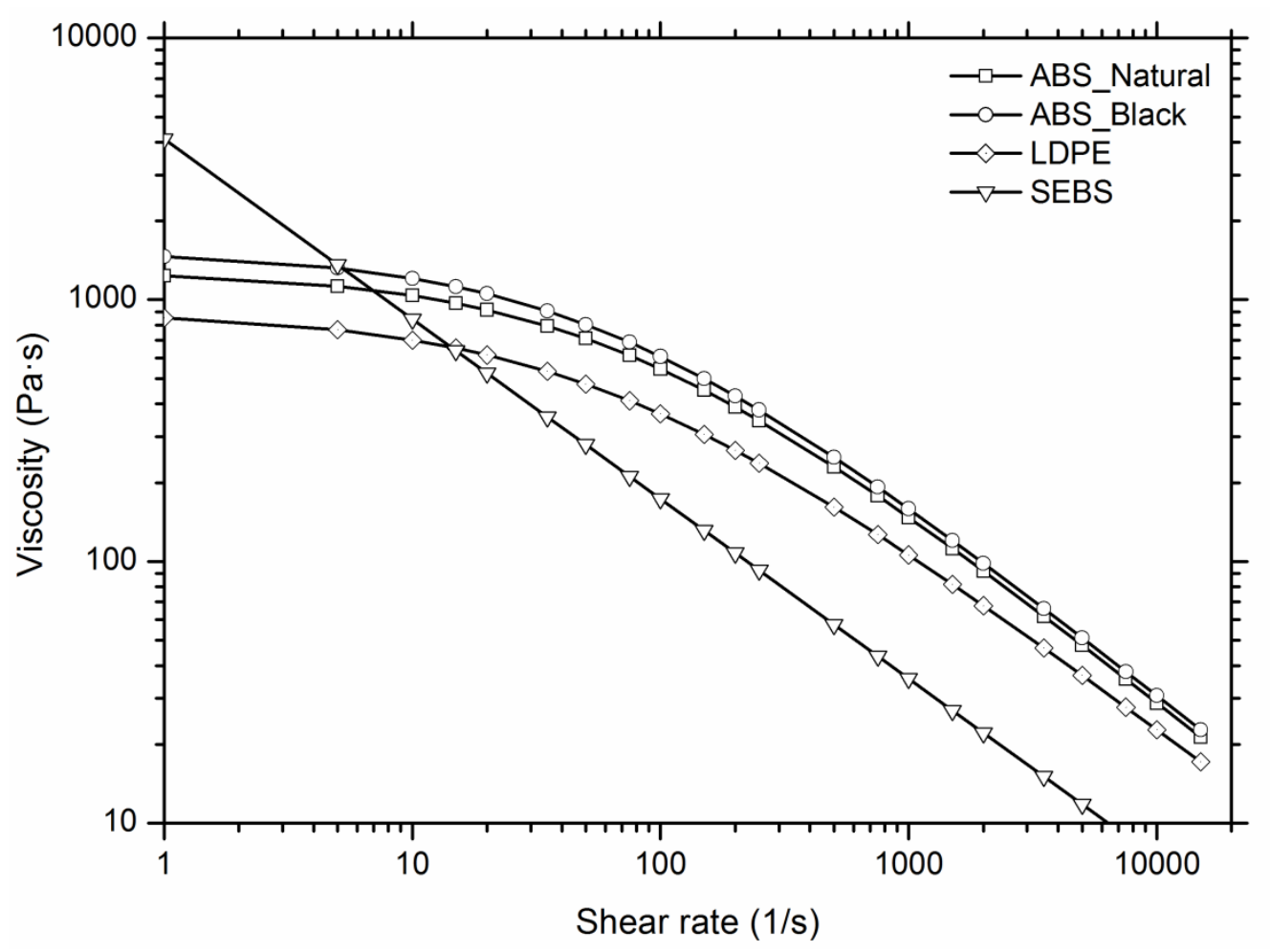

Figure 3. Virgin materials viscosity.

Figure 4 shows the virgin $A B S$ against the ABS/LDPE blend. As can be appreciated, adding LDPE causes a linear decrease of the viscosity as the LDPE percentage increases. This reduction is owed to a lesser viscosity for LDPE and the polymer incompatibility. 


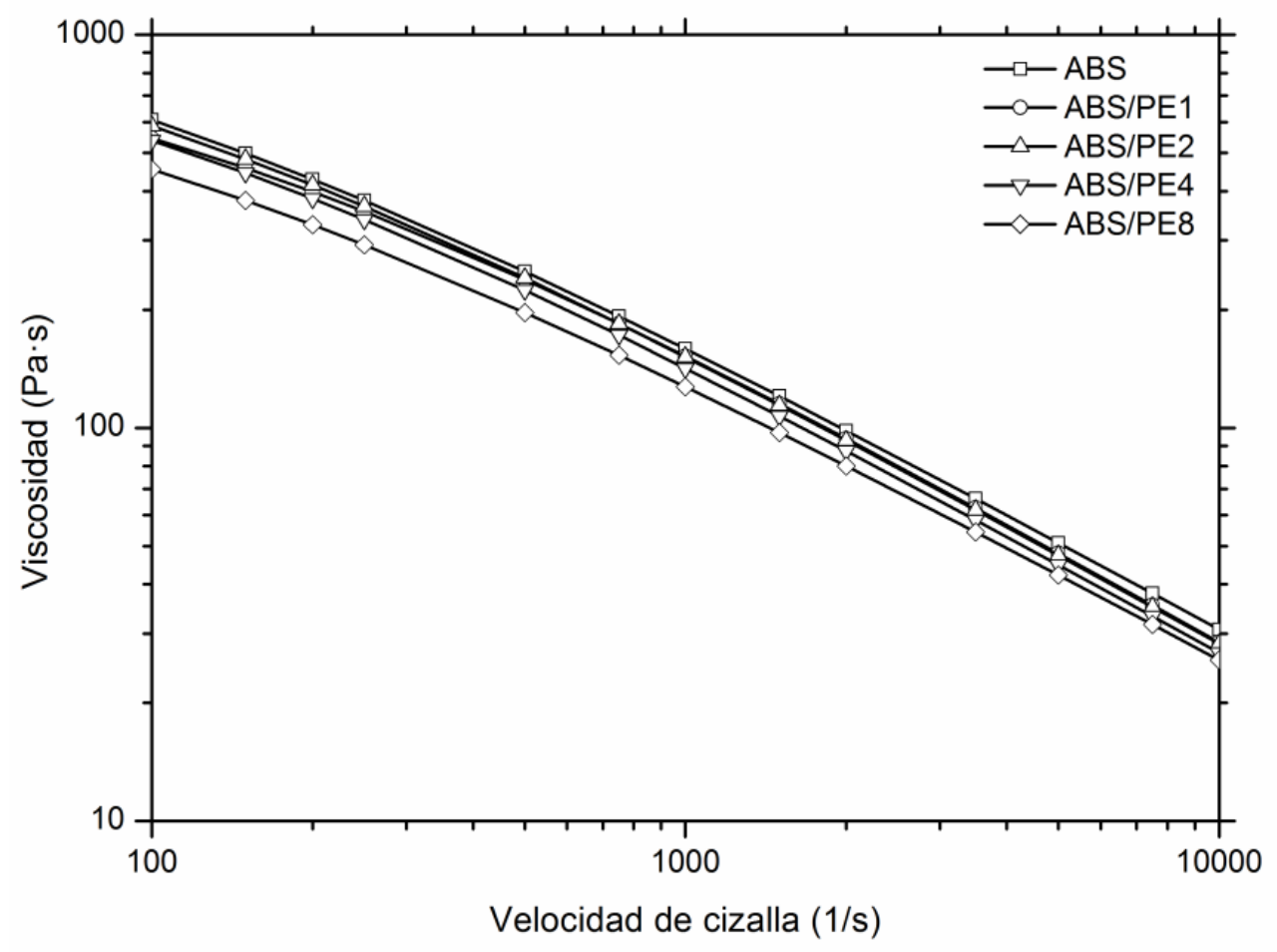

Figure 4. Rheological curves for $A B S$ and $A B S / L D P E$ blends.

\subsubsection{Optical characterization}

Prior to produce the ABS/LDPE and ABS/LDPE/SEBS blends in the extruder several tests were done using an injection machine. Figure 5 shows the obtained specimens. As it is shown, some white marks were produced on ABS/LDPE specimens whereas ABS/LDPE/SEBS specimens yield some bleached bursts. This is due to a bad mixture in the injection machine screw. Therefore, a double screw extruder was used to avoid this problem. Figure 6 shows the results obtained for both ABS grades blended with different LDPE ratios. 


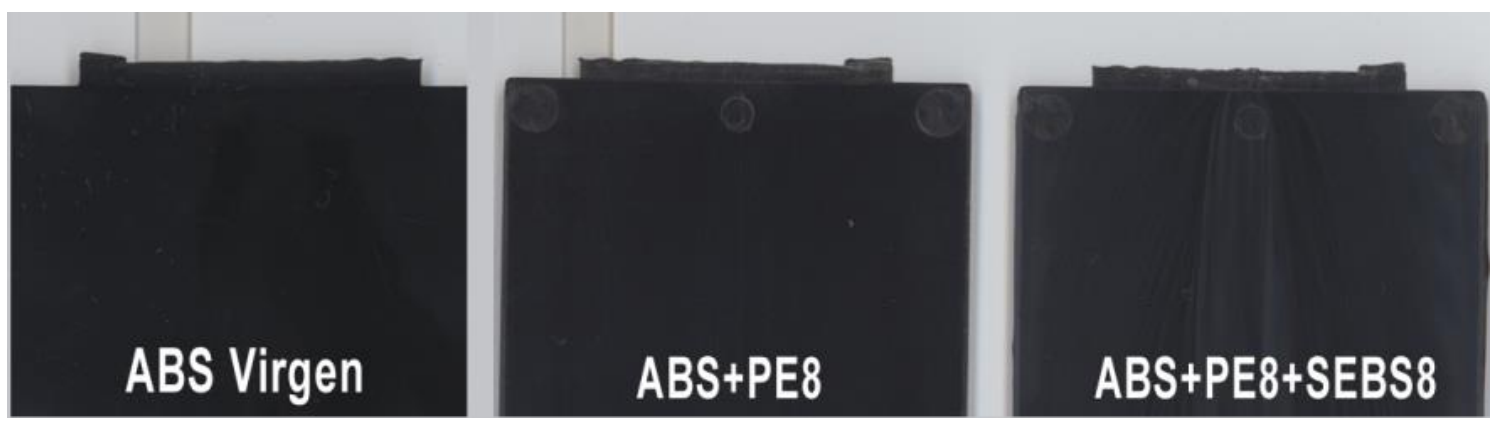

Figure 5. Specimens obtained in the injection machine.

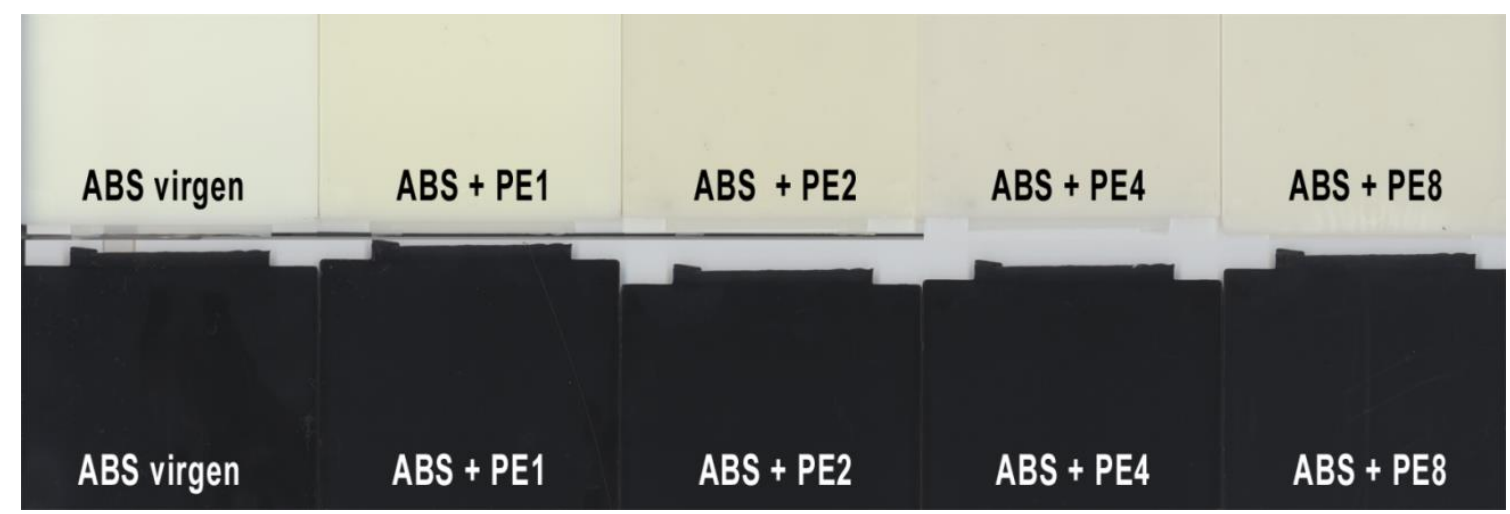

Figure 6. Specimens obtained in the extruder.

Adding LDPE to ABS has two effects. The first one owed to the material reprocessing (darkening) and the second due to the blend itself (whitening). Color changes were measured with a chromatograph, using a CIE $L^{*} a^{*} b^{*}$ scale. Table 3 shows the obtained results. 
Table 3. Color measurements in CIELab scale.

\begin{tabular}{|c|c|c|c|c|c|}
\hline & & $\mathrm{L}^{*}$ & $a^{*}$ & $\mathrm{~b}^{*}$ & $\mathrm{Yi}$ \\
\hline & LDPE_V & $51.63 \pm 2.601$ & $-1.52 \pm 1.257$ & $-6.34 \pm 2.227$ & -23.14 \\
\hline \multirow{5}{*}{ 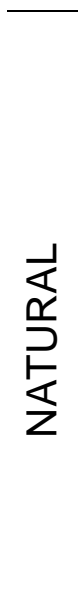 } & ABS_V & $78.95 \pm 0.026$ & $-3.96 \pm 0.029$ & $-0.83 \pm 0.075$ & -5.43 \\
\hline & ABS/PE1 & $78.55 \pm 0.104$ & $-3.12 \pm 0.074$ & $3.60 \pm 0.260$ & 2.89 \\
\hline & ABS/PE2 & $79.05 \pm 0.059$ & $-2.91 \pm 0.010$ & $4.75 \pm 0.044$ & 2.80 \\
\hline & ABS/PE4 & $79.66 \pm 0.025$ & $-3.10 \pm 0.021$ & $2.44 \pm 0.031$ & 2.63 \\
\hline & ABS/PE8 & $80.16 \pm 0.062$ & $-3.32 \pm 0.066$ & $2.35 \pm 0.176$ & 2.23 \\
\hline \multirow{5}{*}{ 爻 } & ABS_V & $26.66 \pm 0.084$ & $0.04 \pm 0.124$ & $-0.96 \pm 0.101$ & -4.80 \\
\hline & ABS/PE1 & $26.87 \pm 0.093$ & $0.04 \pm 0.112$ & $-1.03 \pm 0.065$ & -5.13 \\
\hline & ABS/PE2 & $27.09 \pm 0.023$ & $0.04 \pm 0.109$ & $-1.13 \pm 0.142$ & -5.63 \\
\hline & ABS/PE4 & $27.33 \pm 0.016$ & $0.05 \pm 0.062$ & $-1.27 \pm 0.050$ & -6.30 \\
\hline & ABS/PE8 & $27.79 \pm 0.201$ & $-0.03 \pm 0.147$ & $-1.55 \pm 0.078$ & -7.81 \\
\hline
\end{tabular}

Adding LDPE to both natural and black grades, only modifies the luminance factor $\left(L^{*}\right)$, which is slightly increased, making whiter specimens. Both $a^{*}$ and $b^{*}$ values remain very steady. For black ABS, adding LDPE causes the $L^{*}$ measurements to linearly decrease, while for natural $A B S$ increases the $L^{*}$ values for $2 \%, 4 \%$ and $8 \%$ ratios. This means that, for a small amount of LDPE, the darkening effect is stronger than the whitening one for reprocessed ABS. For larger LDPE quantities, the whitening effect is greater. It should be recalled that, to obtain the specimen, the virgin material has been reprocessed 
one time and the blend twice: the first one in the extruder and the second in the injection machine.

Yellowing measurements (Yi) are shown in Table 3. Natural ABS also exhibits a darkening effect after reprocessing. Yi measurements ran from virgin ABS values to blend ones. However, while increasing the LDPE ratio the yellowing Yi values decrease. For black ABS grade, reprocessing also increases Yi values and LDPE adhesion to black ABS reduces $\mathrm{Yi}$ in a straight relationship with LDPE ratio. As can be noted, the yellowing effect owed to reprocessing is lower for black grade than for natural one. Nevertheless, the yellowing effect due to LDPE blending is greater.

It is widely known that $A B S$ reprocessing causes darkening and yellowing. In a previous work, Karahaliou $[13,14]$ reported this behavior, but only the $L^{*}$ parameter was variable. This can obviously be attributed to chemical interactions and alterations produced during the extrusion process, and are usually associated to the generation of oxidation agents.

\subsubsection{Dimensional characterization.}

Shrinkage analysis of injected parts is very important, since the molded part must fulfill the drawing specifications. A good analysis can foreknow the piece shrinkage, and so the mold size would be increased to compensate the shrinkage. However besides the shrinkage, other potential part deformations should be considered.

Table 4 shows $A, B$ and $C$ measurements over real parts as well as simulation predictions. As can be noted, those parts injected with natural ABS are slightly bigger than with black ABS, regardless of LDPE quantity for any size. 
Therefore, natural ABS injected parts exhibit less shrinkage than the black ones.

Table 4. Part sizes.

\begin{tabular}{|c|c|c|c|c|c|c|c|c|c|}
\hline & & \multicolumn{4}{|c|}{ Real part (mm) } & \multicolumn{4}{|c|}{ Moldfow simulation (mm) } \\
\hline & & $A$ & B & $\mathrm{C}$ & $B-C$ & $A$ & $B$ & C & $B-C$ \\
\hline & MOLDE & $160.000 \pm 0.003$ & $60.000 \pm 0.003$ & $60.000 \pm 0.003$ & 0.000 & 160.000 & 60.000 & 60.000 & 0.000 \\
\hline \multirow{5}{*}{ 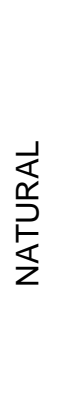 } & ABS_V & $159.316 \pm 0.014$ & $59.825 \pm 0.010$ & $59.725 \pm 0.005$ & 0.100 & 158.947 & 59.700 & 59.532 & 0.168 \\
\hline & ABS/PE1 & $159.282 \pm 0.018$ & $59.812 \pm 0.004$ & $59.717 \pm 0.006$ & 0.095 & 158.914 & 59.690 & 59.521 & 0.169 \\
\hline & ABS/PE2 & $159.276 \pm 0.017$ & $59.795 \pm 0.004$ & $59.706 \pm 0.002$ & 0.089 & 159.015 & 59.730 & 59.555 & 0.175 \\
\hline & ABS/PE4 & $159.250 \pm 0.011$ & $59.775 \pm 0.012$ & $59.669 \pm 0.004$ & 0.106 & 158.872 & 59.680 & 59.480 & 0.200 \\
\hline & ABS/PE8 & $159.161 \pm 0.011$ & $59.738 \pm 0.008$ & $59.646 \pm 0.016$ & 0.092 & 158.824 & 59.660 & 59.480 & 0.180 \\
\hline \multirow{5}{*}{ 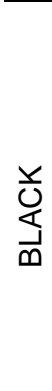 } & ABS_V & $159.255 \pm 0.056$ & $59.794 \pm 0.008$ & $59.695 \pm 0.010$ & 0.099 & 158.947 & 59.700 & 59.532 & 0.168 \\
\hline & ABS/PE1 & $159.237 \pm 0.022$ & $59.787 \pm 0.008$ & $59.679 \pm 0.010$ & 0.108 & 158.914 & 59.690 & 59.521 & 0.169 \\
\hline & ABS/PE2 & $159.216 \pm 0.020$ & $59.778 \pm 0.008$ & $59.648 \pm 0.008$ & 0.130 & 159.015 & 59.730 & 59.555 & 0.175 \\
\hline & ABS/PE4 & $159.173 \pm 0.009$ & $59.752 \pm 0.014$ & $59.630 \pm 0.009$ & 0.122 & 158.872 & 59.680 & 59.480 & 0.200 \\
\hline & ABS/PE8 & $159.149 \pm 0.018$ & $59.718 \pm 0.012$ & $59.612 \pm 0.011$ & 0.106 & 158.824 & 59.660 & 59.480 & 0.180 \\
\hline
\end{tabular}

Shrinkage has been computed using the following equation:

$S=\left(\frac{L_{\text {cavidad }}-L_{\text {pieza }}}{L_{\text {cavidad }}}\right) \times 100$

Figure 7a clearly shows the previously described behavior. However, the most important fact is that shrinkage increases as the LDPE quantity does in the blend. So, the less LDPE contaminated parts, will be smaller. This is a logical outcome since ABS exhibits less shrinkage than LDPE. 
By comparing the real sizes with the simulation results (Figure $7 \mathrm{~b}$ ), it can be noted that they show the same trend, but with a higher shrinkage. There is no difference between natural and black grades since the manufacturer only reported coloration differences.

It can also be seen that the shrinkage were different in each direction. Dimension B suffered a lower shrinkage, followed by $A$ and $C$ sizes.

Based on this observation, it can be concluded that the shrinkage is lower near the injection point (B) than in far zones (C). So, shrinkage mainly depends on the maximum pressure reached inside the cavity, which is higher near the injection point. Moreover, a lower shrinkage in real parts is owed to a higher pressure generation than expected from simulations.

Another thing to consider is that the acceptance criterion is based on the parallelism of both sides. As described above, this problem does not happen when it comes to the test specimens, but it was interesting to study its relationship with the LDPE ratio. Figure 7c shows the difference between $B$ and C sizes. For real parts, this difference is nearly a tenth of a millimeter regardless of the LDPE percentage. The results from simulations were a little higher and also independent of the LDPE ratio.
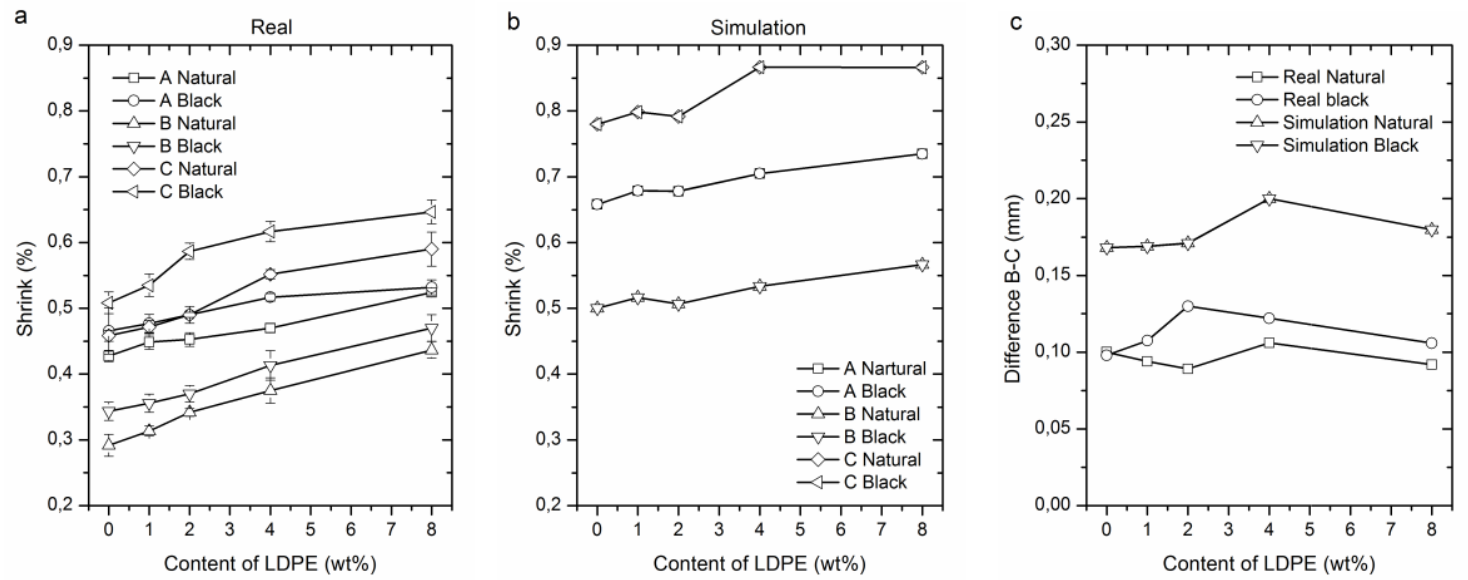

Figure 7. ABS/LDPE blend shrinkage. 
Authors like Chang [15] got similar results. Chang conducted several tests with $127 \cdot 12.8 \cdot 3.18 \mathrm{~mm}$ specimens. The set up temperatures were $218{ }^{\circ} \mathrm{C}$ and $252^{\circ} \mathrm{C}$ and the injection pressures 64 and $71 \mathrm{MPa}$, measuring both longitudinal and transversal to flow shrinkage. Chang also reported that real shrinkages ( $0.76 \%$ avg. longitudinal and $0.51 \%$ avg. transversal) lower than obtained from

simulations ( $1.1 \%$ avg. longitudinal and $0.72 \%$ avg. transversal). Other authors like Shen [16] or Tang [17] studied the shrinkage at different temperatures as well, reporting that higher temperatures produced greater shrinkage while the injection pressure evolved inversely.

\subsection{Study of the influence of the SEBS addition on degraded ABS properties.}

Once the influence of the LDPE contamination on the ABS physical properties was determined, this section will study the effect of adding SEBS to improve the physical properties of ABS with LDPE impurities. This survey will be carried out using a blend of ABS with $8 \%$ LDPE.

\subsubsection{Mechanical characterization.}

Figure 8 shows the relationship between mechanical properties of ABS/PE8 with the SEBS percentage. Adding SEBS improves two of the most spoiled properties: elongation and impact strength. On the contrary, adding SEBS damages the other two properties, taking them away from the virgin material values. Regarding to both grades comparison, the mechanical properties follow the same trend, except for the elongation, which is larger for the black grade. A deeper study shows that the benefits of adding SEBS are greater than their drawbacks. So, for natural ABS, the impact strength (Figure 8d) is increased 
from $65 \%$ to $95 \%$, for black ABS the elongation is increased about $30 \%$ (Figure $8 \mathrm{c}$ ) with $8 \%$ of SEBS. However, adding an $8 \%$ of SEBS caused a $10 \%$ drop over the tensile strength (Figure 8a) and a $7 \%$ in the modulus of elasticity (Figure 8b).

Another aspect to be considered, is the fact that tensile strength, modulus of elasticity and elongation have a quite linear relationship with the SEBS quantity. Nevertheless, the impact strength rises linearly up to $4 \%$ of SEBS and then does not enhance to a significant extent even doubling the SEBS quantity.

From the previous outcomes, it can be stated that the optimum blend for SEBS should be around $4 \%$.

The introduction of SEBS and other elastic thermoplastics was previously reported by other authors like Ganguly [18], Tasdemir [4, 5] and Yin [7] with similar results. 

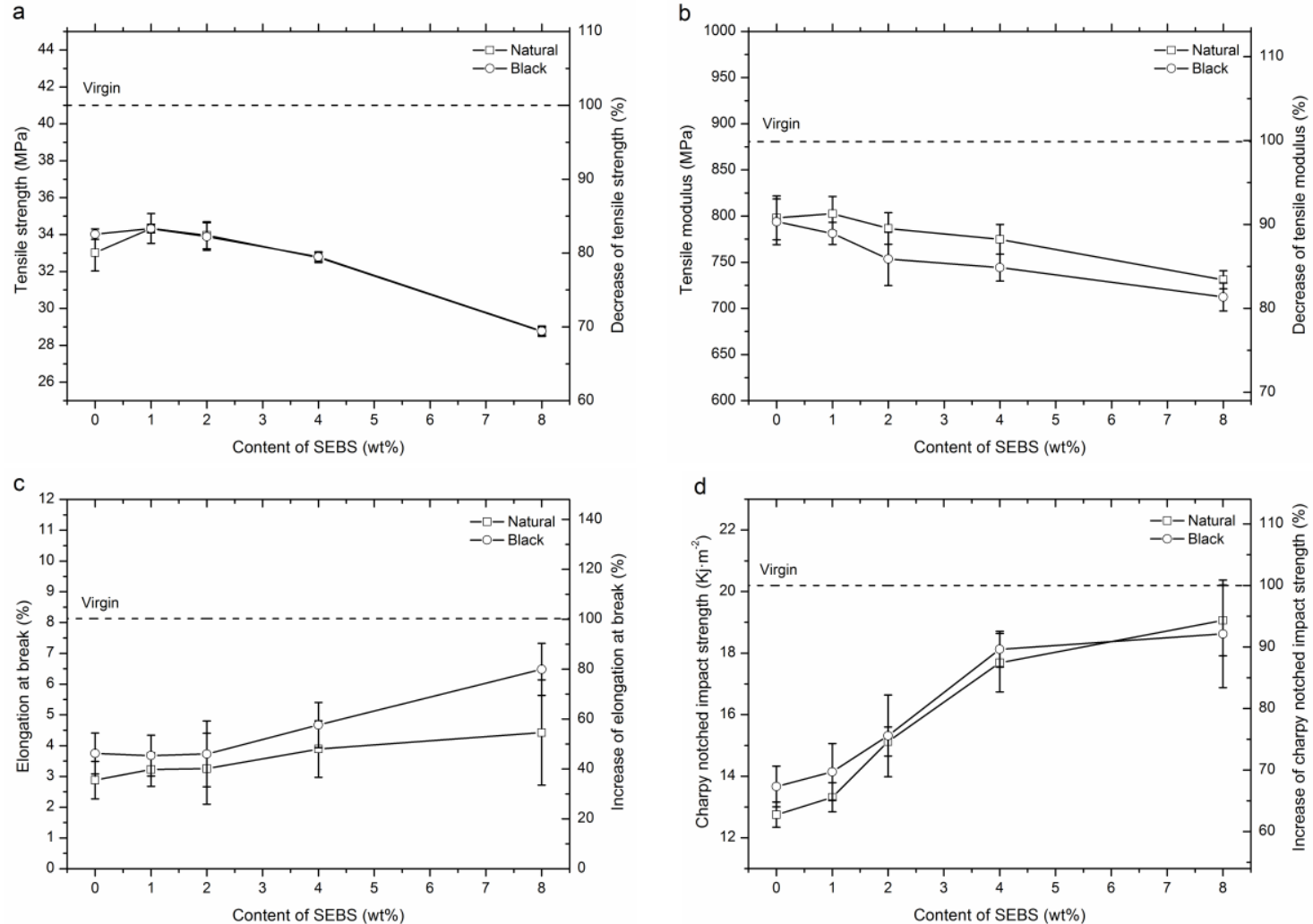

Figure 8. Mechanical properties of ABS/PE8 + SEBS blends.

\subsubsection{Rheological characterization.}

The incorporation of additives to any polymer causes variations in the rheological behavior. In this work, the SEBS presence reduces the viscosity for any specimen (Figure 9). This trend was also reported by Tasdemir [5].

This is due to the low viscosity of SEBS, thus favoring the blend fluidization.

The viscosity drop is not harmful. On the contrary, the more fluid is the material, the easier is the mold injection. 


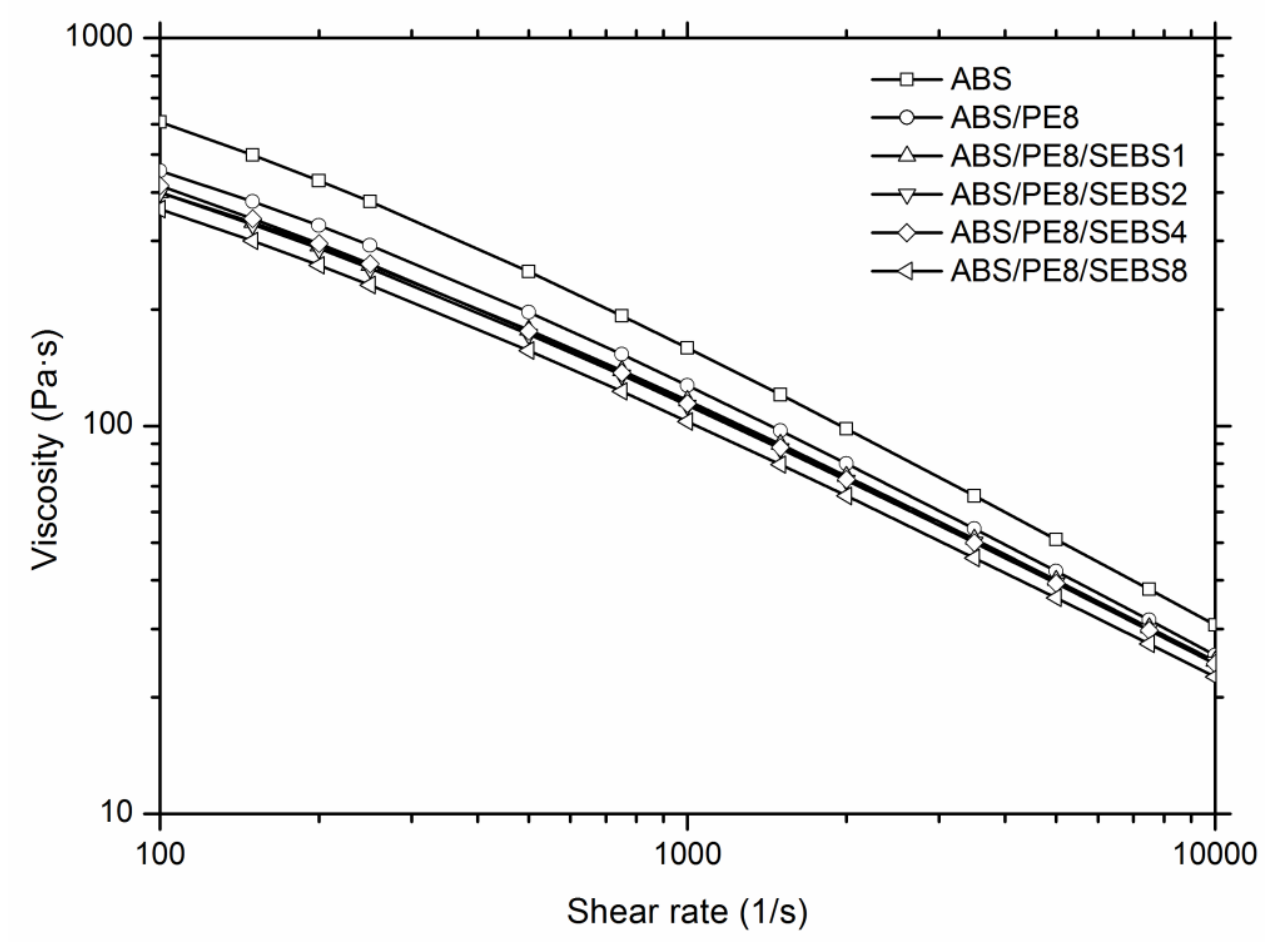

Figure 9. Rheological behavior of ABS/PE8 + SEBS blends.

\subsubsection{Optical characterization}

Figure 10 shows some ABS/PE8 blends specimens where different quantities of SEBS, from $1 \%$ to $8 \%$, where added. The bleaching effect of SEBS can be seen at a glance.

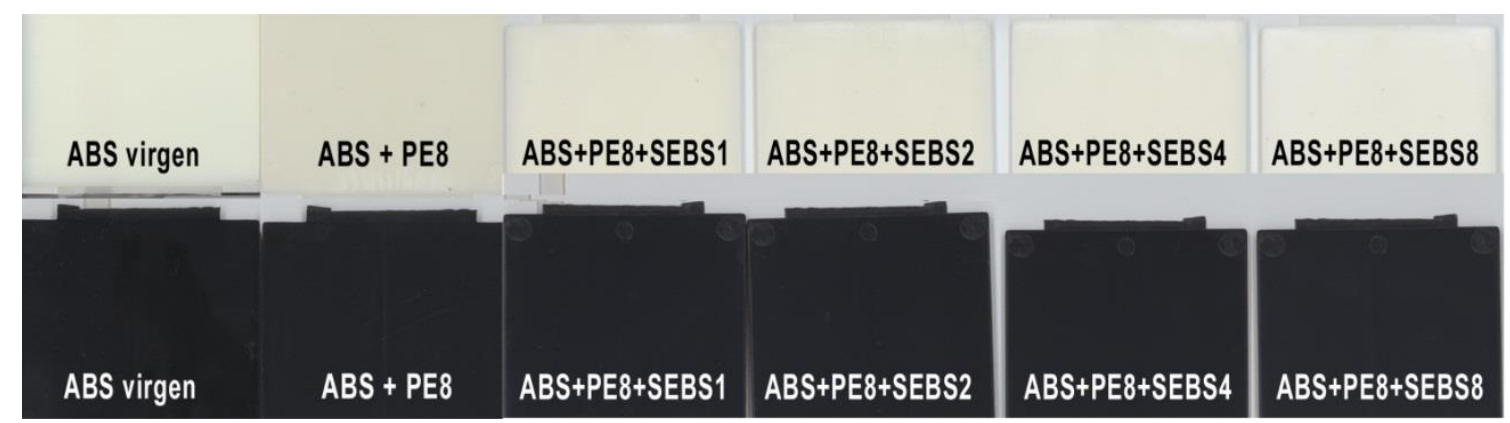

Figure 10. Injection-molded ABS/PE8+SEBS specimens previously blended by extrusion. 
Table 5. Shows the color changes, owed to the SEBS addition, measured using the CIE $L^{*} a^{*} b^{*}$ scale. Adding SEBS to both, natural and black grades, only increases linearly the $L^{*}$ factor producing whiter parts, while $a^{*}$ and $b^{*}$ factors remain steady.

Regarding to the $\mathrm{Yi}$ factor, it can be noted that the SEBS addition linearly decreases this factor as the LDPE ratio increases. It can be seen that the yellowing drop is also greater for the black grade.

Table 5. Color measurements in CIELab scale for SEBS blends.

\begin{tabular}{|c|c|c|c|c|c|}
\hline & & $\mathrm{L}^{*}$ & $a^{*}$ & $b^{*}$ & Yi \\
\hline & LDPE_V & $51.63 \pm 2.601$ & $-1.52 \pm 1.257$ & $-6.34 \pm 2.227$ & -23.14 \\
\hline & SEBS_V & $35.48 \pm 0.297$ & $-0.56 \pm 0.075$ & $0.03 \pm 0.072$ & -0.82 \\
\hline & ABS_V & $78.95 \pm 0.026$ & $-3.96 \pm 0.029$ & $-0.83 \pm 0.075$ & -5.43 \\
\hline & ABS/PE8 & $80.16 \pm 0.062$ & $-3.32 \pm 0.066$ & $2.35 \pm 0.176$ & 2.23 \\
\hline 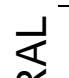 & ABS/PE8/SEBS1 & $81.37 \pm 0.103$ & $-3.41 \pm 0.030$ & $2.09 \pm 0.621$ & 1.57 \\
\hline$E$ & ABS/PE8/SEBS2 & $82.09 \pm 0.049$ & $-3.49 \pm 0.034$ & $2.09 \pm 0.055$ & 1.48 \\
\hline & ABS/PE8/SEBS4 & $83.24 \pm 0.098$ & $-3.38 \pm 0.030$ & $2.17 \pm 0.030$ & 1.74 \\
\hline & ABS/PE8SEBS8 & $84.76 \pm 0.093$ & $-3.33 \pm 0.014$ & $2.11 \pm 0.096$ & 1.62 \\
\hline & ABS_V & $26.66 \pm 0.084$ & $0.04 \pm 0.124$ & $-0.96 \pm 0.101$ & -4.80 \\
\hline & ABS/PE8 & $27.79 \pm 0.201$ & $-0.03 \pm 0.147$ & $-1.55 \pm 0.078$ & -7.81 \\
\hline & ABS/PE8/SEBS1 & $28.11 \pm 0.041$ & $-0.12 \pm 0.071$ & $-1.63 \pm 0.040$ & -8.35 \\
\hline 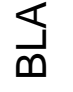 & ABS/PE8/SEBS2 & $28.26 \pm 0.078$ & $-0.14 \pm 0.109$ & $-1.67 \pm 0.133$ & -8.57 \\
\hline & ABS/PE8/SEBS4 & $28.55 \pm 0.038$ & $-0.15 \pm 0.091$ & $-1.79 \pm 0.111$ & -9.11 \\
\hline & ABS/PE8SEBS8 & $29.08 \pm 0.053$ & $-0.25 \pm 0.088$ & $-1.98 \pm 0.104$ & -10.16 \\
\hline
\end{tabular}




\subsubsection{Dimensional characterization.}

Table 6 shows A, B and C sizes for the ABS/PE8 + SEBS specimens (Figure 1). Again, the natural ABS injected parts are slightly larger than the black grade ones, so they had less shrinkage.

The shrinkage was computed using equation (2). Figure 11 shows the computed values for different specimens. Shrinkage values also differ from real parts and simulations, exhibiting the same behavior for each $A, B$ and $C$ dimension. However, the SEBS addition generates a strange behavior. The shrinkage increases up to $1 \%$ of SEBS, but from this ratio it drops when increasing the SEBS percentage, moving closer to virgin ABS values for $8 \%$ SEBS ratios.

Shrinkage increases can be partly explained by the compaction pressure reduction owed to a sprue breakage. So for all SEBS ratios the compaction pressure was lowered. Later, the generation of burrs forced to reduce it even more. This reduction causes the shrinkage increment. However, the shrinkage drop from $4 \%$ to $8 \%$ SEBS ratios is owed to the fluidity rise. This allows a better pressure distribution in the mold cavity, enhancing the part compaction and so reducing its shrinkage. 
Table 6. Part sizes for SEBS blends.

\begin{tabular}{|c|c|c|c|c|c|c|c|c|c|}
\hline & & \multicolumn{4}{|c|}{ Part real (mm) } & \multicolumn{4}{|c|}{ Simulation Moldfow (mm) } \\
\hline & & A & B & $\mathrm{C}$ & $B-C$ & A & B & C & $B-C$ \\
\hline & MOLDE & $160.000 \pm 0.003$ & $60.000 \pm 0.003$ & $60.000 \pm 0.003$ & 0.000 & 160.000 & 60.000 & 60.000 & 0.000 \\
\hline \multirow{6}{*}{ 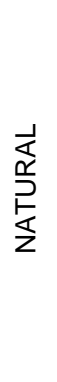 } & ABS_V & $159.316 \pm 0.014$ & $59.825 \pm 0.010$ & $59.725 \pm 0.005$ & 0.100 & 158.947 & 59.700 & 59.532 & 0.168 \\
\hline & ABS/PE8 & $159.161 \pm 0.011$ & $59.738 \pm 0.008$ & $59.646 \pm 0.016$ & 0.092 & 158.824 & 59.660 & 59.480 & 0.180 \\
\hline & ABS/PE8/SEBS1 & $159.116 \pm 0.012$ & $59.702 \pm 0.006$ & $59.604 \pm 0.004$ & 0.098 & 158.803 & 59.650 & 59.473 & 0.177 \\
\hline & ABS/PE8/SEBS2 & $159.134 \pm 0.010$ & $59.708 \pm 0.004$ & $59.615 \pm 0.000$ & 0.093 & 158.849 & 59.670 & 59.488 & 0.182 \\
\hline & ABS/PE8/SEBS4 & $159.179 \pm 0.030$ & $59.722 \pm 0.012$ & $59.646 \pm 0.011$ & 0.076 & 158.838 & 59.670 & 59.482 & 0.188 \\
\hline & ABS/PE8/SEBS8 & $159.237 \pm 0.020$ & $59.756 \pm 0.013$ & $59.696 \pm 0.008$ & 0.060 & 158.814 & 59.660 & 59.474 & 0.186 \\
\hline \multirow{6}{*}{ 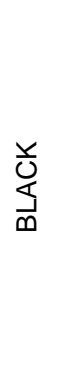 } & ABS_V & $159.255 \pm 0.056$ & $59.794 \pm 0.008$ & $59.695 \pm 0.010$ & 0.099 & 158.947 & 59.700 & 59.532 & 0.168 \\
\hline & ABS/PE8 & $159.149 \pm 0.018$ & $59.718 \pm 0.012$ & $59.612 \pm 0.011$ & 0.106 & 158.824 & 59.660 & 59.480 & 0.180 \\
\hline & ABS/PE8/SEBS1 & $159.087 \pm 0.019$ & $59.692 \pm 0.010$ & $59.585 \pm 0.009$ & 0.107 & 158.803 & 59.650 & 59.473 & 0.177 \\
\hline & ABS/PE8/SEBS2 & $159.092 \pm 0.011$ & $59.690 \pm 0.005$ & $59.589 \pm 0.012$ & 0.101 & 158.849 & 59.670 & 59.488 & 0.182 \\
\hline & ABS/PE8/SEBS4 & $159.121 \pm 0.020$ & $59.695 \pm 0.004$ & $59.619 \pm 0.004$ & 0.076 & 158.838 & 59.670 & 59.482 & 0.188 \\
\hline & ABS/PE8/SEBS8 & $159.165 \pm 0.009$ & $59.719 \pm 0.010$ & $59.657 \pm 0.003$ & 0.062 & 158.814 & 59.660 & 59.474 & 0.186 \\
\hline
\end{tabular}

Figure $11 \mathrm{~b}$ shows the shrinkage results from simulations. Furthermore, in this case, the simulations predicted higher shrinkage values than the real ones. Moreover, the simulations considered the compaction pressure reduction for 1 \% SEBS ratios, which caused even higher shrinkages. They also predicted how increasing the SEBS ratio brought forth the shrinkage, although it did not perform well for SEBS ratios higher than $2 \%$.

As it can be noted in Figure 11c the SEBS adhesion to ABS / LDPE blend causes the difference between $B$ and $C$ dimensions to be even lower and so, the specimen sides are even more parallel. Actually, it is possible to achieve a lesser value than on virgin ABS for SEBS ratios over $8 \%$. This is owed to a better pressure distribution in the mold cavity, which enhances the part compaction and so reduces its shrinkage. 

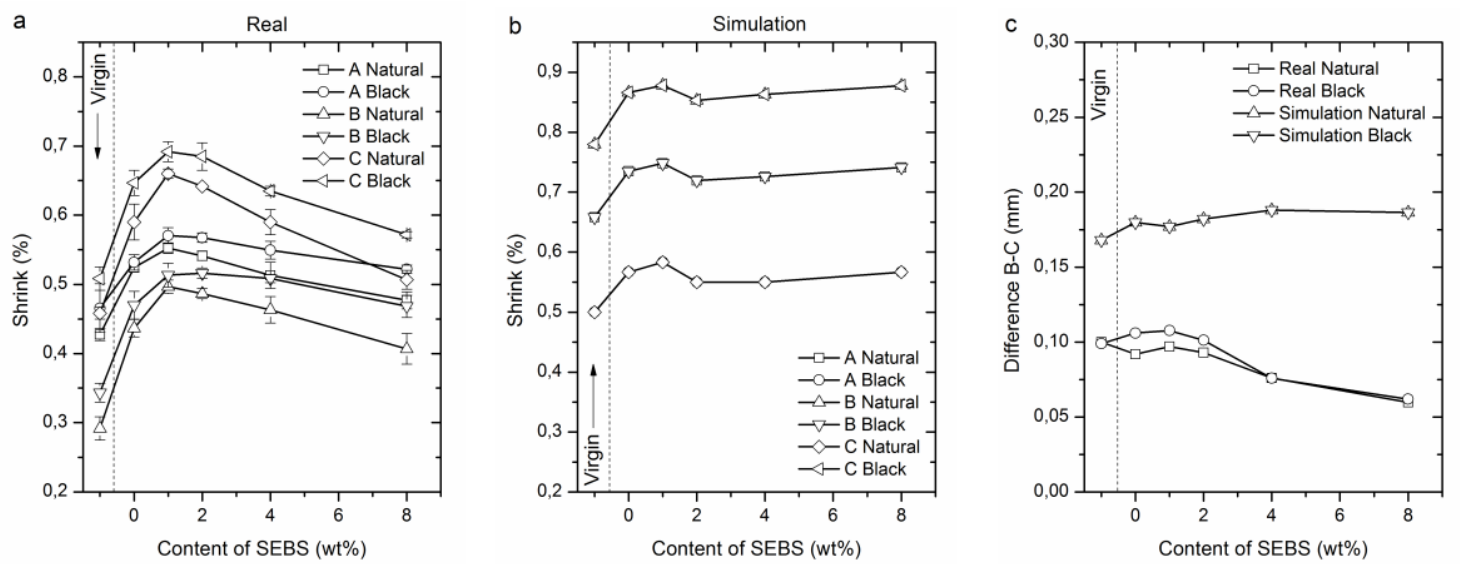

Figure 11. Shrinkage for ABS/PE8 + SEBS blends.

\section{CONCLUSIONS}

The recovery of ABS contaminated with LDPE through SEBS incorporation, brings up the need to study its physical properties to assess the new blend effectiveness.

Regarding to the mechanical properties, the results show how the tensile strength, modulus of elasticity, elongation and impact strength have a linear decrease as the LDPE ratio increases for ABS natural and black grades. Adding SEBS to contaminated ABS allows recovering the elongation and impact strength values up to $30 \%$, approaching them to the virgin $A B S$ values. However, the tensile strength, and the modulus elasticity are not improved, but even reduced.

Regarding to the rheological properties, the LDPE contamination in ABS causes a remarkable viscosity decrease, and adding SEBS to the blend even lowers its viscosity both for Natural and Black grades. This drop is not harmful but quite the reverse. The more fluid is the material, the easier is the mold injection; the lower injection pressure is needed and so, a lower energy is required. Moreover, this allows the temperature and the injection to be decreased during 
manufacturing. These outcomes would allow the manufacturer to raise its productivity and reduce its electric power consumption even more.

With regard to the optical properties, it is remarkable that a double-screw extruder is necessary to make the blend when using black ABS, as a singlescrew extruder would cause white bursts. It should be pointed out that two opposed effects take place: bleaching owed to LDPE addition, and darkening and yellowing due to the reprocessing process. However, the SEBS addition whitens the processed material.

Regarding to the dimensional characterization, the shrinkage increases as the LDPE ratio does, generating slightly smaller parts. For $1 \%$ and $2 \%$ SEBS ratios, the shrinkage remains increasing but from this point it lowers getting closer to virgin ABS values for an $8 \%$ SEBS ratio. Moreover, the SEBS addition to the ABS/LDPE blend makes the B-C difference to be lower, and so the side parallelism is increased. It is possible to achieve differences below the obtained for virgin $A B S$ if the SEBS ratio is greater than $8 \%$.

\section{ACKNOWLEDGEMENTS}

We would like to thank the "Subdirección de Investigación, Desarrollo e Innovación de la Universitat Politècnica de València" for its grant to the research project: "la investigación de sistemas ternarios aplicados a los materiales poliméricos para la mejora de residuos de estireno", Ref.: 20091056 belonging to the research program "primeros proyectos de investigación PAID 06-09" where this work is framed. 


\section{REFERENCES}

[1] Adrados A, de Marco I, Caballero BM, Lopez A, Laresgoiti MF, Torres A. Pyrolysis of plastic packaging waste: A comparison of plastic residuals from material recovery facilities with simulated plastic waste. Waste Management. 2012;32:826-32.

[2] Brebu M, Bhaskar T, Murai K, Muto A, Sakata Y, Uddin MA. Thermal degradation of PE and PS mixed with ABS-Br and debromination of pyrolysis oil by Fe- and Ca-based catalysts. Polymer Degradation and Stability. 2004;84:459-67.

[3] Maris E, Aoussat A, Naffrechoux E, Froelich D. Polymer tracer detection systems with UV fluorescence spectrometry to improve product recyclability. Minerals Engineering. 2012;29:77-88.

[4] Tasdemir M. Properties of acrylonitrile-butadiene-styrene/polycarbonate blends with styrenebutadiene-styrene block copolymer. Journal of Applied Polymer Science. 2004;93:2521-7.

[5] Tasdemir M, Karatop S. Effect of styrene-isopren-styrene addition on the recycled polycarbonate/acrylonitrile-butadiene-styrene polymer blends. Journal of Applied Polymer Science. 2006;101:559-66.

[6] Li B, Wan CY, Zhang Y, Ji JL. Blends of Poly(2,6-dimethyl-1,4-phenylene oxide)/Polyamide 6 Toughened by Maleated Polystyrene-based Copolymers: Mechanical Properties, Morphology, and Rheology. Journal of Applied Polymer Science. 2010;115:3385-92.

[7] Yin NAW, Zhang YX, Zhang Y, Zhang XF, Zhou W. Preparation and properties of PC/SAN alloy modified with styrene-ethylene-butylene-styrene block copolymer. Journal of Applied Polymer Science. 2007;106:637-43.

[8] Oliveira MJ, Brito AM, Costa MC, Costa MF. Gloss and surface topography of ABS: A study on the influence of the injection molding parameters. Polymer Engineering and Science. 2006;46:1394-401.

[9] Peydro MA, Parres F, Crespo JE, Juarez D. Study of Rheological Behavior During the Recovery Process of High Impact Polystyrene Using Cross-WLF Model. Journal of Applied Polymer Science. 2011;120:2400-10.

[10] Salari D, Ranjbar H. Study on the recycling of ABS resins: Simulation of reprocessing and thermooxidation. Iranian Polymer Journal. 2008;17:599-610.

[11] Tiganis BE, Burn LS, Davis P, Hill AJ. Thermal degradation of acrylonitrile-butadiene-styrene (ABS) blends. Polymer Degradation and Stability. 2002;76:425-34.

[12] Arostegui A, Sarrionandia M, Aurrekoetxea J, Urrutibeascoa I. Effect of dissolution-based recycling on the degradation and the mechanical properties of acrylonitrile-butadiene-styrene copolymer. Polymer Degradation and Stability. 2006;91:2768-74.

[13] Karahaliou EK, Tarantili PA. Stability of ABS Compounds Subjected to Repeated Cycles of Extrusion Processing. Polymer Engineering and Science. 2009;49:2269-75.

[14] Karahaliou EK, Tarantili PA. Preparation of Poly(Acrylonitrile-Butadiene-Styrene)/Montmorillonite Nanocomposites and Degradation Studies During Extrusion Reprocessing. Journal of Applied Polymer Science. 2009;113:2271-81.

[15] Chang TC, Faison E. Shrinkage behavior and optimization of injection molded parts studied by the Taguchi method. Polymer Engineering and Science. 2001;41:703-10.

[16] Shen CY, Wang LX, Li Q. Optimization of injection molding process parameters using combination of artificial neural network and genetic algorithm method. Journal of Materials Processing Technology. 2007;183:412-8.

[17] Tang SH, Tan YJ, Sapuan SM, Sulaiman S, Ismail N, Samin R. The use of Taguchi method in the design of plastic injection mould for reducing warpage. Journal of Materials Processing Technology. 2007;182:418-26.

[18] Ganguly A, Saha S, Bhowmick AK, Chattopadhyay S. Augmenting the performance of acrylonitrilebutadiene-styrene plastics for low-noise dynamic applications. Journal of Applied Polymer Science. 2008;109:1467-75. 


\section{Figure Captions}

Figure 12. Molded part geometry

Figure 13. Mechanical properties of ABS/LDPE blends for Natural and Black Grades.

Figure 14. Virgin materials viscosity

Figure 15. Rheological curves for ABS and ABS/LDPE blends

Figure 16. Specimens obtained in the injection machine

Figure 17. Specimens obtained in the extruder

Figure 18. ABS/LDPE blend shrinkage

Figure 19. Mechanical properties of ABS/PE8 + SEBS blends.

Figure 20. Rheological behavior of ABS/PE8 + SEBS blends

Figure 21. Injection-molded ABS/PE8+SEBS specimens previously blended by extrusion

Figure 22. Shrinkage for ABS/PE8 + SEBS blends

\section{Table Captions}

Table 7. Materials used at present work

Table 8. Mechanical properties data given by the manufacturers

Table 9. Color measurements in CIELab scale

Table 10. Part sizes

Table 11. Color measurements in CIELab scale for SEBS blends

Table 12. Part sizes for SEBS blends 